\title{
Cost-Effectiveness of Primary HPV Testing, Cytology and Co-testing as Cervical Cancer Screening for Women Above Age 30 Years
}

\author{
Xian Wen Jin, MD, PhD' , Laura Lipold, $M D^{2}$, Julie Foucher, $B S^{3}$, Andrea Sikon, MD', \\ Jennifer Brainard, $M D^{4}$, Jerome Belinson, $M D^{5}$, Sarah Schramm, $M A^{6}$, Kelly Nottingham, $M P H^{6,7}$, \\ Bo Hu, PhD ${ }^{8}$, and Michael B. Rothberg, MD, MPH
}

\begin{abstract}
'Department of Internal Medicine, Cleveland Clinic, Cleveland, OH, USA; ${ }^{2}$ Department of Family Medicine, Cleveland Clinic, Cleveland, OH, USA; ${ }^{3}$ Cleveland Clinic Lerner College of Medicine, Cleveland Clinic, Cleveland, OH, USA; ${ }^{4}$ Department of Pathology, Cleveland Clinic, Cleveland, OH, USA; ${ }^{5}$ Department of Obstetrics and Gynecology, Cleveland Clinic, Cleveland, OH, USA; ${ }^{\circ}$ Medicine Institute Center for Value Based Care Research, Cleveland Clinic, Cleveland, OH, USA; ${ }^{7}$ Heritage College of Osteopathic Medicine, Ohio University, Athens, OH, USA; ${ }^{8}$ Department of Quantitative Health Science, Cleveland Clinic, Cleveland, OH, USA.
\end{abstract}

BACKGROUND: Cervical cancer screening guidelines for women aged $\geq 30$ years allow for co-testing or primary cytology testing. Our objective was to determine the test characteristics and costs associated with Cytology, HPV and Co-testing screening strategies.

MAIN METHODS: Retrospective cohort study of women undergoing cervical cancer screening with both cytology and HPV (Hybrid Capture 2) testing from 2004 to 2010 in an integrated health system. The electronic health record was used to identify women aged $\geq 30$ years who had cotesting. Unsatisfactory or unavailable test results and incorrectly ordered tests were excluded. The main outcome was biopsy-proven cervical intraepithelial neoplasia grade 3 or higher (CIN3+).

KEY RESULTS: The final cohort consisted of 99,549 women. Subjects were mostly white $(78.4 \%)$, married $(70.7 \%)$, never smokers $(61.3 \%)$ and with private insurance (86.1\%). Overall, $5121(5.1 \%)$ tested positive for HPV and 6115 (6.1\%) had cytology $\geq$ ASCUS; 1681 had both and underwent colposcopy and 310 (0.3\%) had CIN3+. Sensitivity for CIN3+ was $91.9 \%$ for Primary $\mathrm{Cy}$ tology, 99.4\% for Co-testing, and $94.8 \%$ for Primary HPV; specificity was $97.3 \%$ for Co-testing and Primary Cytology and $97.9 \%$ for Primary HPV. Over a 3-year screening interval, Primary HPV detected more cases of CIN3+ and was less expensive than Primary Cytology. Co-testing detected 14 more cases of CIN3+ than Primary HPV, but required an additional 100,277 cytology tests and 566 colposcopies at an added cost of \$2.38 million, or $\$ 170,096$ per additional case detected.

CONCLUSIONS: Primary HPV was more effective and less expensive than Primary Cytology. Primary HPV screening appears to represent a cost-effective alternative to Co-testing.

J Gen Intern Med 31(11):1338-44

DOI: $10.1007 / \mathrm{s} 11606-016-3772-5$

(c) Society of General Internal Medicine 2016

Electronic supplementary material The online version of this article (doi:10.1007/s11606-016-3772-5) contains supplementary material, which is available to authorized users.

Received December 11, 2015

Revised May 2, 2016

Accepted June 7, 2016

Published online July 14, 2016

\section{INTRODUCTION}

Cervical cancer is the fourth leading cause of cancer death in women worldwide, with an estimated 275,000 deaths each year. ${ }^{1,2}$ Incidence of cervical cancer in the US has decreased $>50 \%$ because of the success of the Papanicolaou (Pap) test (cytology screening). As a result, cervical cancer mortality has also declined by half. ${ }^{3}$ The American Cancer Society estimates 4100 cervical cancer deaths in the US in 2015 , most due to lack of screening or follow-up from abnormal testing. ${ }^{4}$

Elucidation of the role of high-risk human papillomavirus (HPV) in cervical cancer pathogenesis has led to incorporation of HPV testing into primary screening strategies for women age 30 and older. ${ }^{5}$ When cytology and HPV tests are used together (co-testing), sensitivity approaches $100 \%,{ }^{6}$ and the 5year risk of cervical intraepithelial neoplasia grade 3 or higher (CIN3+) after a negative co-test is far below that with negative cytology alone, supporting longer testing intervals. ${ }^{7,8}$ For this age group, multiple organizations now recommend co-testing every 5 years as an alternative to cytology. ${ }^{5,9-11}$ The American Cancer Society, The American Society of Colposcopy and Cervical Pathology (ASCCP) and the American Society of Clinical Pathology recommend co-testing as a "preferred" screening strategy, ${ }^{5}$ although the appropriateness of this recommendation has been questioned. ${ }^{12}$ The US Preventive Service Task Force (USPSTF) recommends cytology or cotesting as acceptable screening. Co-testing is more expensive, but estimates of cost-effectiveness are lacking in the US. ${ }^{13}$

Several studies support the use of primary HPV testing (HPV followed by cytology for positive HPV results) due to its high sensitivity and negative predictive value. ${ }^{6,14-22}$ One systematic review suggests that co-testing has only marginal benefit over primary HPV testing, with significantly increased cost. $^{23}$ In 2014, the Food and Drug Administration (FDA) approved the cobas ${ }^{\circledR}$ HPV Test (Roche Molecular Systems) for primary screening in women age 25 and older, and an interim guidance panel of the ASCCP and the Society of Gynecologic Oncology (SGO) stated that high-risk HPV testing could be considered an alternative to guidelinerecommended options. ${ }^{24}$ 
Despite FDA approval, a number of concerns remain. Some worry that primary HPV testing may not be sufficiently sensitive and cases will be missed, especially because it has not been studied in routine practice. ${ }^{25}$ Many institutions do not use the cobas ${ }^{\circledR}$ Test and may be reluctant to change based on a single trial. Finally, the cost-effectiveness of primary HPV screening is unknown. To investigate the utility of primary HPV screening strategies in clinical practice, we compared the expected outcomes and cost of a Primary HPV strategy using the most widely used HPV test (Hybrid Capture 2) to those of Co-testing and Primary Cytology in an integrated health system.

\section{METHODS}

We conducted a retrospective cohort study of women $\geq 30$ years of age who had co-testing with HPV DNA and cytology for primary cervical cancer screening in an integrated health system from 2004 to 2010 . This study was approved by the Cleveland Clinic Institutional Review Board. Patients who had diagnostic tests incorrectly ordered as screening or whose HPV or cytology results were unsatisfactory or unavailable were excluded. The electronic health record (Epic $₫$ EHR) was queried to identify eligible patients and extract demographics. The primary outcome of histologically confirmed CIN3+ was chosen because it is reliably diagnosed, ${ }^{26-28}$ has a low likelihood of regression ${ }^{29,30}$ and is a surrogate for cancer. ${ }^{7} \mathrm{~A}$ supplemental analysis was performed using the outcome of
CIN2+. ${ }^{6} \mathrm{CIN} 3+$ was identified from the pathology reporting system (CoPath). HPV and cytology results were obtained through chart review. For women with CIN3+ lesions, the results of the co-test immediately preceding cervical biopsy were recorded. For women without histologically confirmed CIN3+ lesions, we recorded the results of the most recent cotest. To accurately determine prevalence, positive and negative predictive values, patients with abnormal screening tests who did not undergo colposcopy were identified and their outcomes assigned using multiple imputation.

Cytology specimens were analyzed by the ThinPrep Imaging System ${ }^{\mathrm{TM}}$ (Hologic). Results were reported according to the 2001 Bethesda System. ${ }^{31}$ HPV status was determined utilizing Hybrid Capture 2 (Qiagen) as either positive or negative for HPV genotypes 16, 18, 31, 33, 35, 39, 45, 51, 52, 56, 58, 59 and $68 .{ }^{32}$ HPV-16/HPV-18 genotypes were not distinguished from other genotypes.

Using HPV and cytology results, we modeled three primary screening strategies (Fig. 1) from the payer perspective. The first two, Primary Cytology and Co-testing, reflect current recommendations for women age 30 and older. ${ }^{5,9,10,13}$ In the third strategy, Primary HPV, positive HPV results are followed by cytology, while negative HPV results prompt no testing for 5 years.

In the model, only patients with positive HPV and cytology $\geq$ atypical squamous cells of undetermined significance (ASCUS) are referred to colposcopy. Patients with positive HPV and normal cytology receive repeat co-testing in 1 year.
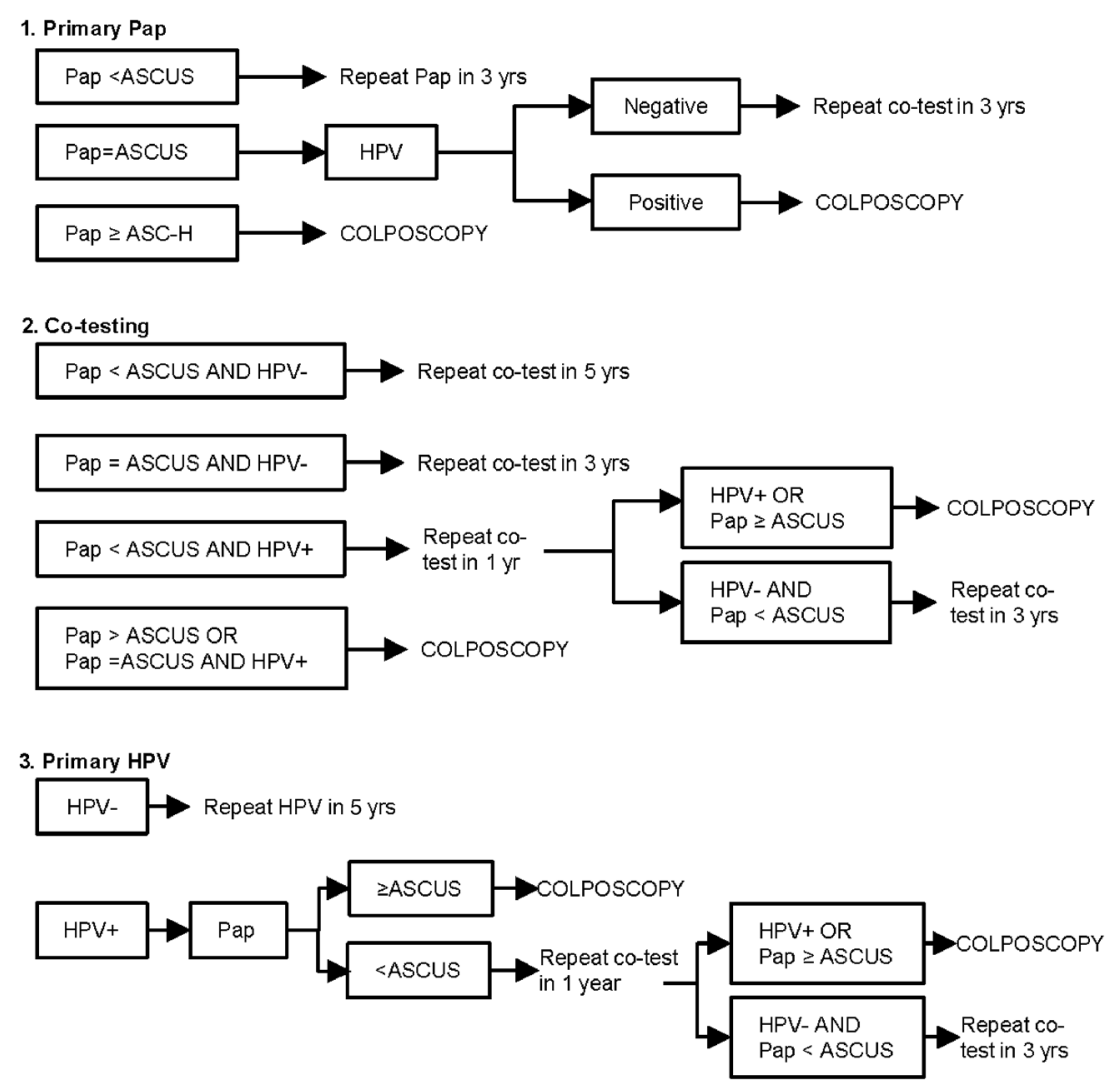

Figure 1 Screening strategies for primary cervical cancer screening adapted from the ASCCP Guidelines ${ }^{11}$. ASCCP American Society for Colposcopy and Cervical Pathology, HPV human papillomavirus, ASCUS atypical cells of undetermined significance 
Patients remaining HPV positive or $\geq$ ASCUS at 1 year are referred to colposcopy. Referred patients who do not undergo colposcopy do not incur colposcopy costs and cannot have CIN3+ detected, even if present. Sensitivity, specificity and predictive values of the strategies were based on observed results, without imputation. To determine the costs associated with detection of a case of $\mathrm{CIN} 3+$ we performed a simulation based on the results of the recorded HPV test, cytology test and the known $\mathrm{CIN} 3+$ outcome. We assumed that all patients with a follow-up test would have CIN3+ detected if present. For patients who were HPV negative in the primary HPV strategy, or HPV negative and cytology negative in the co-test strategy, we assumed no further testing, and CIN3+ would not be detected, even if present. In reality, two of these women had additional testing (e.g., repeat cytology or HPV test in $<3$ years) and were found to have CIN3+, so no strategy detected all cases. To determine costs, we summed the number of HPV tests, cytology tests and colposcopies for each strategy over a 3year interval and assigned costs using current Medicare National Facility Prices (eTable 1). ${ }^{33}$ For Co-testing and Primary HPV, we multiplied the cost of the 5 -year interval by $3 / 5$. Office visit costs were not included because we assumed that testing would be conducted during an annual examination. For the Primary Cytology and Primary HPV strategies, we assumed that both HPV and cytology specimens would be collected but the secondary specimen would be processed only in the case of a positive primary result. Costs to store unprocessed cytology specimens could not be ascertained and were not included. The collection kit represents approximately $10 \%$ of the cost of the test. In a sensitivity analysis, we varied the storage cost from 10 to $30 \%$ of the cost of cytology. We estimated colposcopy costs based on a weighted average of Medicare prices for colposcopy procedure codes in our study population. This analysis was limited to one round of screening and did not include the cost of surveillance following colposcopy.

\section{STATISTICAL ANALYSIS}

Baseline characteristics were summarized as frequencies and percentages. Characteristics of patients who were referred and did or did not undergo colposcopy were compared using the chi-squared test. For referred patients who did not undergo colposcopy ( $n=375), \mathrm{CIN} 3+$ results were imputed based on a logistic regression model that used the observed CIN3+ results among the entire cohort as outcomes and baseline characteristics and HPV and cytology results as predictors. Results were imputed five times and summarized using Rubin's rule. Similar analyses were performed to impute $\mathrm{CIN} 2+$ results.

Prevalence of $\mathrm{CIN} 2+/ \mathrm{CIN} 3+$ was estimated as percentages with $95 \%$ confidence intervals. Test characteristics were estimated for the initial round of screening. Analyses were conducted using SAS 9.3 (Cary, NC) and R 3.0.2 (cran.r-project.org).

\section{RESULTS}

We identified 101,889 patients who met the inclusion criteria. We excluded patients with diagnostic testing ordered as screening $(N=35)$ and those with unsatisfactory or unavailable test results $(N=2305)$, resulting in a final cohort of 99,549 patients. Patient characteristics appear in Table 1.

Table 1 Demographics $(N=99,549)$

\begin{tabular}{|c|c|c|c|c|c|c|c|c|}
\hline \multirow[b]{2}{*}{ Characteristic } & \multicolumn{2}{|l|}{ All } & \multicolumn{2}{|c|}{ HPV + } & \multicolumn{2}{|c|}{ CIN3+ } & \multicolumn{2}{|c|}{ CIN2+ } \\
\hline & $\mathbf{N}$ & $\%^{*}$ & $\mathbf{N}$ & $\%^{\dagger}$ & $\mathbf{N}$ & $\%^{\dagger}$ & $\mathbf{N}$ & $\%^{\dagger}$ \\
\hline \multicolumn{9}{|l|}{ Age } \\
\hline $30-39$ & 28,819 & $28.9 \%$ & 2377 & $8.2 \%$ & 161 & $0.6 \%$ & 380 & $1.3 \%$ \\
\hline $40-49$ & 29,965 & $30.1 \%$ & 1423 & $4.7 \%$ & 62 & $0.2 \%$ & 164 & $0.5 \%$ \\
\hline $50-59$ & 25,401 & $25.5 \%$ & 879 & $3.5 \%$ & 29 & $0.1 \%$ & 79 & $0.3 \%$ \\
\hline$\geq 60$ & 15,364 & $15.4 \%$ & 442 & $2.9 \%$ & 17 & $0.1 \%$ & 38 & $0.2 \%$ \\
\hline \multicolumn{9}{|l|}{ Race } \\
\hline White & 78,076 & $78.4 \%$ & 3676 & $4.7 \%$ & 197 & $0.3 \%$ & 480 & $0.6 \%$ \\
\hline Black & 13,234 & $13.3 \%$ & 982 & $7.4 \%$ & 50 & $0.4 \%$ & 128 & $1.0 \%$ \\
\hline Other & 8239 & $8.3 \%$ & 463 & $5.6 \%$ & 22 & $0.3 \%$ & 53 & $0.6 \%$ \\
\hline \multicolumn{9}{|l|}{ Marital status ${ }^{\ddagger}$} \\
\hline Single/Widowed and age $<50$ & 19,041 & $19.3 \%$ & 1776 & $9.3 \%$ & 77 & $0.4 \%$ & 202 & $1.1 \%$ \\
\hline Married/domestic partner/widowed and age $\geq 50$ & 69,662 & $70.7 \%$ & 2234 & $3.2 \%$ & 146 & $0.2 \%$ & 327 & $0.5 \%$ \\
\hline Divorced/separated & 9782 & $9.9 \%$ & 1043 & $10.7 \%$ & 39 & $0.4 \%$ & 122 & $1.2 \%$ \\
\hline \multicolumn{9}{|l|}{ Smoking status } \\
\hline Smoke/passive smoker & 12,254 & $12.4 \%$ & 1131 & $9.2 \%$ & 61 & $0.5 \%$ & 140 & $1.1 \%$ \\
\hline Former smoker & 25,836 & $26.2 \%$ & 1299 & $5.0 \%$ & 85 & $0.3 \%$ & 183 & $0.7 \%$ \\
\hline Never smoked & 60,391 & $61.3 \%$ & 2621 & $4.3 \%$ & 122 & $0.2 \%$ & 336 & $0.6 \%$ \\
\hline Unknown & 62 & $0.1 \%$ & 6 & $9.7 \%$ & 0 & $0.0 \%$ & 1 & $1.6 \%$ \\
\hline \multicolumn{9}{|l|}{ Insurance } \\
\hline Medicaid & 1050 & $1.1 \%$ & 113 & $10.8 \%$ & 10 & $1.0 \%$ & 28 & $2.7 \%$ \\
\hline Medicare & 11,684 & $12.6 \%$ & 448 & $3.8 \%$ & 22 & $0.2 \%$ & 45 & $0.4 \%$ \\
\hline Private & 79,735 & $86.1 \%$ & 3992 & $5.0 \%$ & 218 & $0.3 \%$ & 542 & $0.7 \%$ \\
\hline Self-pay & 161 & $0.2 \%$ & 39 & $24.2 \%$ & 11 & $6.8 \%$ & 31 & $19.3 \%$ \\
\hline
\end{tabular}

HPV human papillomavirus, CIN2+ cervical intraepithelial neoplasia 2 or worse, CIN3+ cervical intraepithelial neoplasia 3 or worse

*Percentages are with respect to the total sample size

tPercentages are with respect to the sample size in the corresponding category of the characteristic

tMissing data not reported 
Subjects were mostly under age $60(84.6 \%)$, white $(78.4 \%)$, married $(70.7 \%)$, never smokers $(61.3 \%)$ and with private insurance $(86.1 \%)$. A total of 8836 patients $(8.9 \%)$ had a positive test by either HPV $(N=5121,5.1 \%)$ or cytology $(N=6115,6.1 \%)$. Of these, 1681 underwent colposcopy, and $310(0.3 \%)$ had CIN3+ lesions (Table 2). Both positive HPV and $\mathrm{CIN} 3+$ were more common among women who were younger, black, single and smokers. Additionally, 375 patients had positive cytology but did not undergo colposcopy. These patients were not different in age or marital status from those who underwent colposcopy; however they were more likely to be white, to smoke and to not have private insurance $(p<0.001)$ (eTable 2). Of these patients, we imputed 139 cases of CIN2+ and 74 cases of CIN $3+$. Eleven cancers were reported - two metastatic breast and nine cervical (1 squamous, 8 adenocarcinoma).

The incidence of CIN3+ by HPV and cytology status appears in Table 2. CIN3+ was more common with positive than negative HPV results $(5.7 \%$ vs. $0.02 \%, p<0.001)$. HPVpositive patients with abnormal cytology had high rates of CIN3+ $(\geq 4.6 \%)$. Of patients who were HPV negative, only those with cytology indicating ASC-H, HSIL and cancer had rates of $\mathrm{CIN} 3+>0.6 \%$. Only two HPV-negative patients with any other cytology result had CIN3+.

Test characteristics appear in Table 3. Sensitivity of Co-testing (99.4 \%) was greater than for Primary HPV $(94.1 \%)$ and Primary Cytology $(90.7 \%)$. Primary HPV was slightly more specific $(98.1 \%)$ than the other strategies (both $97.6 \%$ ) and had the greatest positive predictive value $(12.1 \%$ vs. $9.6 \%$ for Primary Cytology and $10.3 \%$ for Co-testing). All strategies had negative predictive values exceeding $99.9 \%$.

Over a 3-year period, Primary HPV was the least expensive, detecting 294 cases of CIN3+ with 2422 colposcopies per 99,549 screened at a cost of $\$ 3.47$ M. Primary Cytology detected nine fewer cases of CIN3+ but cost more. Co-testing detected 14 additional cases of CIN3+ than Primary HPV but would require 100,277 more cytology tests and 566 more colposcopies at an additional cost of $\$ 2.38$ million, or

Table 2 CIN3+ Incidence by Cytology and HPV Results

\begin{tabular}{|c|c|c|c|c|}
\hline & \multicolumn{2}{|c|}{ CIN3+/HPV positive } & \multicolumn{2}{|c|}{ CIN3+/HPV negative } \\
\hline & Incidence & $\%(95 \% \mathrm{CI})$ & Incidence & $\%(95 \% \mathrm{CI})$ \\
\hline & $294 / 5121$ & & & $0.02(0.01,0.03)$ \\
\hline \multicolumn{5}{|c|}{ Cytology status ${ }^{*}$} \\
\hline Negative & $22 / 2721$ & $0.8(0.5,1.2)$ & $2 / 90,713$ & $0(0,0.009)$ \\
\hline ASCUS & $46 / 924$ & $5.0(3.7,6.6)$ & $1 / 3150$ & $0.03(0,0.2)$ \\
\hline ASC-H & $35 / 144$ & $24.3(17.7,32.3)$ & $4 / 87$ & $4.6(1.5,12.0)$ \\
\hline AGC & $14 / 57$ & $24.6(14.5,38.0)$ & $0 / 268$ & $0(0,1.8)$ \\
\hline LSIL & $34 / 734$ & $4.6(3.3,6.5)$ & $1 / 147$ & $0.6(0,4.3)$ \\
\hline HSIL & $94 / 201$ & $\begin{array}{l}46.8(39.8, \\
53.9)\end{array}$ & $5 / 17$ & $\begin{array}{l}29.4(11.4, \\
56.0)\end{array}$ \\
\hline Cancer & $8 / 8$ & $100(60,100)$ & $3 / 3$ & $100(31,100)$ \\
\hline \multicolumn{5}{|c|}{$\begin{array}{l}\text { HPV human papillomavirus, CIN3+cervical intraepithelial neoplasia } 3 \\
\text { or worse, ASCUS atypical squamous cells of undetermined significance, } \\
\text { ASC-H atypical squamous cells-cannot exclude high-grade } \\
\text { intraepithelial lesion, AGC atypical glandular cells, LSIL low-grade } \\
\text { squamous intraepithelial lesion, HSIL high-grade squamous } \\
\text { intraepithelial lesion }\end{array}$} \\
\hline
\end{tabular}

$\$ 170,096$ per case detected (Table 4). In sensitivity analysis, this marginal cost ranged from $\$ 166,864-\$ 173,327$ as the cost of the HPV test was varied from 50 to $150 \%$ of the current Medicare National Facility Price (eTable 6). Increasing the cost of cytology made Co-testing even more expensive, whereas including costs for cytology storage in the Primary $H P V$ strategy decreased the marginal cost of Co-testing. Varying the storage cost from 10 to $30 \%$ of the cost of cytology produced marginal costs of $\$ 157,566$ to $\$ 132,506$. Results were similar for patients with CIN2+ (eTables 3-6).

\section{DISCUSSION}

The FDA approval of a primary HPV screening test as an alternative to cytology has introduced complexity into an evolving field and stirred considerable debate over the appropriate screening strategy. ${ }^{12,25,34}$ In this retrospective cohort study of 99,549 patients undergoing primary cervical cancer screening in an integrated health system, we found that Primary $H P V$ screening was more effective and less expensive than Primary Cytology. Co-testing was only slightly more effective than Primary $H P V$ testing and was substantially more expensive, costing approximately $\$ 170,000$ for each additional case of CIN3+ identified.

Three large prospective, population-based studies of cervical cancer screening have been conducted in North America. All reported rates of HPV infection and cervical abnormalities similar to ours. ${ }^{6,716,35-37}$ In contrast, test characteristics of the strategies varied widely. The sensitivity of HPV testing ranged from 48 to $87 \%$, and cytology ranged from 51 to $90 \%$. Specificity varied less, ranging from 92 to $99 \%$ for HPV and $88 \%$ to $99 \%$ for cytology. In our cohort, all testing modalities had high sensitivity $(>90 \%)$ and specificity ( $>97 \%)$. In contrast, the ATHENA study and Canadian Cervical Cancer Screening Trial reported sensitivities below $60 \%$ for all modalities, because their rates of abnormal cytology (which was necessary for advancing to colposcopy in any strategy) were much lower than ours. It is unclear whether this difference was due to sample collection or pathological interpretation.

The superior cost-effectiveness of cervical cancer screening strategies involving HPV testing over cytology alone has been reported in a variety of settings. ${ }^{38-44}$ Although Co-testing is preferred over Primary Cytology by some guidelines, ${ }^{5}$ this recommendation has been questioned. ${ }^{12}$ Our analysis supports a Primary HPV strategy over Primary Cytology, because it detected more cases of $\mathrm{CIN} 3+$ at lower cost. The higher specificity of Primary HPV meant almost $20 \%$ fewer unnecessary colposcopies - a savings of $\$ 1.3$ million over the study period. Compared to Co-testing, Primary HPV avoided most Pap smears and many colposcopies. Because both strategies included HPV testing, the analysis was relatively insensitive to the cost of HPV testing.

To our knowledge, no studies have directly compared 3year Primary HPV and Co-testing strategies, and none have 
Table 3 Test Characteristics of Three Screening Strategies for Detecting CIN3+

\begin{tabular}{|c|c|c|c|}
\hline & Primary cytology ${ }^{*}, \dagger$ & Co-testing ${ }^{*} \uparrow$ & Primary $\mathrm{HPV}^{*}, \dagger$ \\
\hline Sensitivity $(\%, 95 \%$ CI $)$ & $\begin{array}{l}90.7(86.4,93.8) \\
244 / 269\end{array}$ & $\begin{array}{l}99.3(97.1,99.9)^{\S} \\
267 / 269\end{array}$ & $\begin{array}{l}94.1(90.3,96.5) \\
253 / 269\end{array}$ \\
\hline Specificity $(\%, 95 \%$ CI $)$ & $\begin{array}{l}97.6(97.5,97.7) \\
96,559 / 98,905\end{array}$ & $\begin{array}{l}97.6(97.5,97.7) \\
96,559 / 98,905\end{array}$ & $\begin{array}{l}98.1(98.1,98.2)^{\|} \\
97.068 / 98,905\end{array}$ \\
\hline $\operatorname{PPV}(\%, 95 \% \mathrm{CI})^{*}$ & $\begin{array}{l}9.6(8.4,10.8)^{\mathrm{II}} \\
285 / 2965\end{array}$ & $\begin{array}{l}10.3(9.1,11.5)^{\mathrm{I}} \\
308 / 2988\end{array}$ & $\begin{array}{l}12.1(10.7,13.6)^{\mathrm{II}} \\
294 / 2422\end{array}$ \\
\hline $\operatorname{NPV}(\%, 95 \% \mathrm{CI})^{*}$ & $\begin{array}{l}99.97(99.96,99.98) \\
96,559 / 96,584\end{array}$ & $\begin{array}{l}100(99.99,100)^{\S} \\
96,559 / 96,561\end{array}$ & $\begin{array}{l}99.98(99.97,99.99) \\
97,111 / 97,127\end{array}$ \\
\hline
\end{tabular}

HPV human papillomavirus, CIN3+ cervical intraepithelial neoplasia 3 or worse

*We assume that the tests conducted after year 1 are perfect in the sense that all test positives are true CIN3+ cases, and all negatives are true negatives † Numerators and denominators rounded to nearest integers

Includes imputed data for patients with missing colposcopy results

$\$ p<0.001$ vs. Primary Cytology and Primary HPV, other comparisons not significant

$\dddot{I I}_{p}<0.001$ vs. Primary Cytology and Co-testing, other comparisons not significant

$p<0.001$ for all comparisons

included US populations. Several studies utilized mathematical models to simulate the natural history of cervical cancer and evaluate the cost-effectiveness of screening strategies. One Canadian study compared a primary HPV strategy with a 3-year screening interval and a co-testing strategy to cytology alone. ${ }^{38}$ However, they did not directly compare these strategies to each other, and an incremental cost-effectiveness could not be ascertained. Another Canadian study found that compared to primary HPV, bi-annual co-testing beginning at age 18 had an incremental cost-effectiveness ratio of $>\$ 400,000$ per life year gained. ${ }^{45}$ Similar findings have been demonstrated in Europe. ${ }^{46-49}$ Because our findings cannot be translated into life years saved, the incremental costeffectiveness of co-testing may be difficult to interpret. What is a reasonable cost for the health care system to bear to detect one additional case of CIN3+? Specifically, is the detection of 14 cases per 100,000 women screened worth $\$ 170,096$ per case detected, in addition to the inconvenience of an additional 100,277 cytology tests and 566 colposcopies?

Our cohort represents a low-risk population, as evidenced by the lower incidence of LSIL $(0.88 \%)$ and HSIL $(0.22)$ than the national median $\left(2.5 \%\right.$ and $0.5 \%$, respectively). ${ }^{50}$ Our study is instructive for other integrated health systems seeking to provide high-value care to similar populations. Given the low rates of disease, the redundancy of co-testing appears to be unnecessary. This conclusion cannot be generalized to high-risk centers, where patients struggle with access to care, and where most cases of cervical cancer occur. In that context, the emphasis must be on consistent screening and assuring timely follow-up.

Our study has several other important limitations. First, for women who did not receive follow-up care, we used imputation to assign outcomes, which may not accurately represent the incidence of $\mathrm{CIN} 3+$. The population with imputed results was small, but differed in race, smoking status and insurance from those who underwent colposcopy. Imputation was used only for determining the positive and negative predictive value, so it had no impact on other test characteristics or the cost-effectiveness calculations. Second, without being able to determine the histological status of patients with both negative HPV and cytology tests, our study is susceptible to verification bias; however, other studies have demonstrated negligible incidence of $\mathrm{CIN} 2+$ and $\mathrm{CIN} 3+$ in the setting of negative co-testing results. ${ }^{6,51,52} \mathrm{We}$ used only a single co-test, while the importance of assessing screening over at least two rounds has been suggested. ${ }^{53}$ Additionally, because all tests were conducted in a high-functioning health care system, test sensitivity may be superior to other settings. Finally, because we used surrogate outcomes, we could not estimate the cost per case of cervical cancer prevented or life years saved.

Our cost-effectiveness analysis is limited to a 3-year screening interval. Because of the difference in screening intervals (3 years for Primary Cytology and 5 years for Primary HPV and Co-testing), we had to estimate the cost of a 3-year interval for the HPV-based strategies in order to compare like outcomes. The cost of storing specimens was considered only in sensitivity analysis. Including such costs would improve the cost-effectiveness of Co-testing. It is also important to note that we used current National Medicare Facility Prices. While the prices paid by private insurance may be higher, our marginal costs of Co-Testing over Primary HPV were relatively insensitive to the cost of HPV testing. Higher cytology prices would make Co-Testing less favorable. Our analysis was

Table 4 Number of Tests and Cost by Strategy for Detecting CIN3+ $(N=99,549)$

\begin{tabular}{llllllccc}
\hline \hline & \#HPV & \#Cytology & \#Colposcopy & 3-Year total cost & CIN3+ cases & $\Delta$ Cost & $\Delta$ Cases & Marginal cost/Case \\
\hline Primary cytology & 6359 & 101,649 & 2966 & $\$ 4,795,900$ & 285 & \\
Primary HPV & 102,270 & 7842 & 2422 & $\$ 3,472,320$ & 294 & $-\$ 1,323,580$ & 9 \\
Co-testing & 108,119 & 108,119 & 2988 & $\$ 5,853,660$ & 308 & $\$ 147,064$ & $\$ 2,381,340$ & 14 \\
\hline
\end{tabular}

HPV human papillomavirus, CIN3+ cervical intraepithelial neoplasia 3 or worse

*Total cost of Primary HPV and Co-testing strategies multiplied by 3/5 to compare cost of 3-year screening interval for all strategies 
conducted from the payer perspective. Patients, depending on their co-pays and financial means, might feel differently about which strategy they prefer. Finally, we excluded patients who had equivocal HPV results. Including the cost of these tests would not affect the outcome because the number would be the same for both strategies.

The cobas ${ }^{\circledR}$ HPV Test was recently approved for primary cervical cancer screening based on the ATHENA trial. ${ }^{21,54}$ Like the Hybrid Capture 2 used in this study, the cobas ${ }^{\circledR}$ Test detects 14 high-risk HPV genotypes. However, the cobas ${ }^{\circledR}$ Test also detects genotype 66 and indicates specifically whether the specimen is positive or negative for HPV-16 or HPV-18. ${ }^{55}$ The strong association of cervical cancer with these two genotypes is the basis for a primary HPV screening strategy in which women who test positive for HPV-16/HPV-18+ genotypes are triaged directly for colposcopy. In ATHENA, genotyping for HPV-16/HPV-18 improved the sensitivity for CIN3+ and required far fewer cytology tests with only a marginal increase in colposcopies over co-testing. ${ }^{35}$ This should make Primary HPV testing even more cost-effective. However, because of the differences between these tests, our Primary HPV strategy is not directly comparable to screening with cobas ${ }^{\circledR}$.

The findings from this large cohort of women in routine care shed light upon the changing landscape of cervical cancer screening. Primary HPV testing appears to offer an attractive tradeoff between cost and effectiveness. Additional factors may be taken into consideration when selecting the appropriate screening strategy for individual patients, but as valuebased care becomes increasingly important, cost and convenience will contribute more to decision making. Overall, the findings from this study provide support for the implementation of primary HPV screening with reflex cytology as a potentially cost-effective strategy in low-risk women age 30 and older.

Author Contributions: Dr. Jin and Sarah Schramm had full access to all of the data in the study and take responsibility for the integrity of the data and the accuracy of the data analysis.

Study concept and design: Jin, Sikon, Lipold, Belinson

Acquisition of data: Schramm, Nottingham, Brainard

Analysis and interpretation of data: Hu, Jin, Lipold, Sikon, Rothberg, Foucher

Drafting of the manuscript: Jin, Foucher, Rothberg, Sikon, Lipold

Critical revision of the manuscript for important intellectual content: All authors

Statistical analysis: $\mathrm{Hu}$

Administrative, technical, or material support: Schramm, Nottingham Study supervision: Schramm, Nottingham, Jin, Sikon, Lipold

Role of the Sponsor: The sponsors provided funding only and played no role in the design and conduct of the study; collection, management, analysis, and interpretation of the data; preparation, review, or approval of the manuscript; or decision to submit the manuscript for publication.

Additional Contributions: The following individuals contributed to acquisition of data: Jacqueline Fox, RN, BSN; Pamela Mason, RN, BSN, MBA; Fabrizio Galimberti, PhD; Yumeng Li, BS; Yue Zhao, BS; Joanna Zhou, BS; Mir Lim; Shoshana Weiner, MD; Harsha Alexander, MD
Previous Presentation: Oral Presentation at the Society of General Internal Medicine Annual Meeting, San Diego, April 25, 2014

Corresponding Author: Xian Wen Jin, $M D, P h D$; Department of Internal MedicineCleveland Clinic, Cleveland, OH, USA (e-mail:jinx@ccf.org).

\section{Compliance with Ethical Standards:}

Funding/Support: This study was funded internally by the Cleveland Clinic Research Program Committees, award number 2010-1050-R1.

Conflict of Interest: Xian Wen Jin MD, PhD: Speaking Bureau for Biagen and Merck. Jerome Belinson MD: Support in kind (reagents and testing) and funds for direct support and research, under the auspices of Preventive Oncology International Inc., from Hologic Inc., Qiagen, Gen-Probe, Merck Inc., BGI Shenzhen, and GE Healthcare. None of the support described above was for the research described in this manuscript. All remaining authors declare that they do not have a conflict of interest.

\section{REFERENCES}

1. International Agency for Research on Cancer GLOBOCAN 2012: Estimated Cancer Incidence, Mortality, and Prevalence Worldwide in 2012. Available at: http://globocan.iarc.fr/Pages/fact_sheets_cancer.aspx. Accessed 31 May 2016.

2. Arbyn M, Castellsagué $\mathbf{X}$, de Sanjosé $\mathbf{S}$, et al. Worldwide burden of cervical cancer in 2008. Ann Oncol Off $\mathrm{J}$ Eur Soc Med Oncol ESMO. 2011;22(12):2675-86. doi:10.1093/annonc/mdr015.

3. National Cancer Institute. SEER cancer statistics review, 1975-2009 (vintage 2009 populations). Available at: http://seer.cancer.gov/csr/ 1975_2009_pops09. Accessed May 31, 2016.

4. American Cancer Society. Cancer Facts \& Figures 2015. 2015.

5. Saslow D, Solomon D, Lawson HW, et al. American Cancer Society, American Society for Colposcopy and Cervical Pathology, and American Society for Clinical Pathology screening guidelines for the prevention and early detection of cervical cancer. CA Cancer J Clin. 2012;62(3):147-72. doi: 10.3322/caac.21139.

6. Mayrand M-H, Duarte-Franco E, Rodrigues I, et al. Human papillomavirus DNAversus Papanicolaou screening tests for cervical cancer. N Engl J Med. 2007;357(16):1579-88. doi:10.1056/NEJMoa071430.

7. Katki HA, Schiffman M, Castle PE, et al. Benchmarking CIN 3+ risk as the basis for incorporating HPV and Pap cotesting into cervical screening and management guidelines. J Low Genit Tract Dis. 2013;17(5 Suppl 1):S28-35. doi:10.1097/LGT.0b013e318285423c.

8. Rijkaart DC, Berkhof J, Rozendaal L, et al. Human papillomavirus testing for the detection of high-grade cervical intraepithelial neoplasia and cancer: final results of the POBASCAM randomised controlled trial. Lancet Oncol. 2012;13(1):78-88. doi:10.1016/S1470-2045(11)70296-0.

9. Moyer VA, US Preventive Services Task Force. Screening for cervical cancer: US Preventive Services Task Force recommendation statement. Ann Intern Med. 2012;156(12):880-91. doi:10.7326/0003-4819-156-12-20120619000424 . W312.

10. Committee on Practice Bulletins-Gynecology. ACOG Practice Bulletin Number 131: screening for cervical cancer. Obstet Gynecol. 2012;120(5):1222-38. doi:10.1097/AOG.0b013e318277c92a.

11. Massad LS, Einstein MH, Huh WK, et al. 2012 updated consensus guidelines for the management of abnormal cervical cancer screening tests and cancer precursors. Obstet Gynecol. 2013;121(4):829-46. doi:10.1097/ AOG.Ob013e3182883a34.

12. Smith-McCune K. Choosing a screening method for cervical cancer: Papanicolaou testing alone or with human papillomavirus testing. JAMA Intern Med. 2014;174(7): 1027-8. doi:10.1001/jamainternmed.2014.1368.

13. Schiffman M, Solomon D. Clinical practice. Cervical-cancer screening with human papillomavirus and cytologic cotesting. N Engl J Med. 2013;369(24):2324-31. doi:10.1056/NEJMcp1210379.

14. Cuzick J, Clavel C, Petry K-U, et al. Overview of the European and North American studies on HPV testing in primary cervical cancer screening. Int J Cancer. 2006;119(5):1095-101. doi:10.1002/ijc.21955.

15. Cuzick J, Szarewski A, Cubie H, et al. Management of women who test positive for high-risk types of human papillomavirus: the HART study. Lancet. 2003;362(9399): 1871-6. doi:10.1016/S0140-6736(03)14955-0.

16. Katki HA, Kinney WK, Fetterman B, et al. Cervical cancer risk for women undergoing concurrent testing for human papillomavirus and 
cervical cytology: a population-based study in routine clinical practice. Lancet Oncol. 2011;12(7):663-72. doi:10.1016/S1470-2045(11)70145-0.

17. Anttila A, Kotaniemi-Talonen L, Leinonen M, et al. Rate of cervical cancer, severe intraepithelial neoplasia, and adenocarcinoma in situ in primary HPV DNA screening with cytology triage: randomised study within organised screening programme. BMJ. 2010;340:c1804.

18. Leinonen $\mathbf{M}$, Nieminen $\mathbf{P}$, Kotaniemi-Talonen L, et al. Age-specific evaluation of primary human papillomavirus screening vs conventional cytology in a randomized setting. J Natl Cancer Inst. 2009;101(23):161223. doi:10.1093/jnci/djp367.

19. Sankaranarayanan R, Nene BM, Shastri SS, et al. HPV screening for cervical cancer in rural India. N Engl J Med. 2009;360(14):1385-94. doi:10.1056/NEJMoa0808516.

20. Ronco G, Dillner J, Elfström KM, et al. Efficacy of HPV-based screening for prevention of invasive cervical cancer: follow-up of four European randomised controlled trials. Lancet. 2013. doi:10.1016/S0140-6736(13)62218-7.

21. Castle PE, Stoler MH, Wright TCJ, Sharma A, Wright TL, Behrens CM. Performance of carcinogenic human papillomavirus (HPV) testing and HPV 16 or HPV 18 genotyping for cervical cancer screening of women aged 25 years and older: a subanalysis of the ATHENA study. Lancet Oncol. 2011;12(9):880-90. doi:10.1016/S1470-2045(11)70188-7.

22. Dillner J, Rebolj M, Birembaut $\mathbf{P}$, et al. Long term predictive values of cytology and human papillomavirus testing in cervical cancer screening: joint European cohort study. BMJ. 2008;337:a1754

23. Vesco KK, Whitlock EP, Eder M, et al. Screening for Cervical Cancer: A Systematic Evidence Review for the US Preventive Services Task Force. Rockville (MD): Agency for Healthcare Research and Quality (US); 2011. http://www.ncbi.nlm.nih.gov/books/NBK66099/. Accessed 31 May 2016.

24. Huh WK, Ault KA, Chelmow D, et al. Use of primary high-risk human papillomavirus testing for cervical cancer screening: interim clinical guidance. Gynecol Oncol. 2015;136(2):178-82. doi:10.1016/j.ygyno.2014.12.022.

25. Feldman S. Human papillomavirus testing for primary cervical cancer screening: is it time to abandon Papanicolaou testing? JAMA Intern Med. 2014;174(10):1539-40. doi:10.1001/jamainternmed.2014.4021.

26. Stoler MH, Schiffman M. Atypical Squamous Cells of Undetermined Significance-Low-grade Squamous Intraepithelial Lesion Triage Study (ALTS) Group. Interobserver reproducibility of cervical cytologic and histologic interpretations: realistic estimates from the ASCUS-LSIL Triage Study. JAMA J Am Med Assoc. 2001;285(11):1500-5.

27. Castle PE, Stoler MH, Solomon D, Schiffman M. The relationship of community biopsy-diagnosed cervical intraepithelial neoplasia grade 2 to the quality control pathology-reviewed diagnoses: an ALTS report. Am J Clin Pathol. 2007;127(5):805-15. doi:10.1309/PT3PNC1QL2F4D2VL.

28. Carreon JD, Sherman ME, Guillén D, et al. CIN2 is a much less reproducible and less valid diagnosis than CIN3: results from a histological review of population-based cervical samples. Int $\mathrm{J}$ Gynecol Pathol Off $\mathrm{J}$ Int Soc Gynecol Pathol. 2007;26(4):441-6. doi:10.1097/pgp.0b013e31805152ab.

29. Castle PE, Schiffman M, Wheeler CM, Solomon D. Evidence for frequent regression of cervical intraepithelial neoplasia-grade 2. Obstet Gynecol. 2009;113(1):18-25. doi:10.1097/AOG.0b013e31818f5008.

30. Moscicki A-B, Ma Y, Wibbelsman C, et al. Rate of and risks for regression of cervical intraepithelial neoplasia 2 in adolescents and young women. Obstet Gynecol. 2010;116(6):1373-80. doi:10.1097/AOG.0b013e3181fe777f.

31. Solomon D, Davey D, Kurman R, et al. The 2001 Bethesda system: terminology for reporting results of cervical cytology. JAMA J Am Med Assoc. 2002;287(16):2114-9.

32. Qiagen. digene HC2 High-Risk HPV DNATest. Available at: http://www.qiagen com/products/catalog/assay-technologies/complete-assay-kits/hpv-testing/ digene-hc2-high-risk-hpv-dna-test\#productdetails. Accessed 31 May 2016.

33. Centers for Medicare and Medicaid Services. Fee Schedules - General Information. Available at: http://www.cms.gov/Medicare/Medicare-Fee-forService-Payment/FeeScheduleGenInfo/index.html. Accessed 31 May 2016.

34. Perkins RB, Stier EA. Should US women be screened for cervical cancer with pap tests, HPV tests, or both? Ann Intern Med. 2014;161(4):295-7. doi:10.7326/M14-1043.

35. Cox JT, Castle PE, Behrens CM, et al. Comparison of cervical cancer screening strategies incorporating different combinations of cytology, HPV testing, and genotyping for HPV 16/18: results from the ATHENA HPV study. Am J Obstet Gynecol. 2013;208(3):184.e1-e184.e11. doi:10.1016/j.ajog.2012.11.020.

36. Whitlock EP, Vesco KK, Eder M, Lin JS, Senger CA, Burda BU. Liquidbased cytology and human papillomavirus testing to screen for cervical cancer: a systematic review for the US Preventive Services Task Force. Ann
Intern Med. 2011;155(10):687-97. doi:10.7326/0003-4819-155-10201111150-00376. W214-W215.

37. Mayrand M-H, Duarte-Franco E, Coutlée F, et al. Randomized controlled trial of human papillomavirus testing versus Pap cytology in the primary screening for cervical cancer precursors: design, methods and preliminary accrual results of the Canadian cervical cancer screening trial (CCCaST). Int J Cancer. 2006;119(3):615-23. doi:10.1002/ijc.21897.

38. Vijayaraghavan A, Efrusy MB, Mayrand M-H, Santas CC, Goggin P. Cost-effectiveness of high-risk human papillomavirus testing for cervical cancer screening in Québec, Canada. Can J Public Health. 2010;101(3):220-5.

39. Vijayaraghavan A, Efrusy M, Lindeque G, Dreyer G, Santas C. Cost effectiveness of high-risk HPV DNA testing for cervical cancer screening in South Africa. Gynecol Oncol. 2009;112(2):377-83. doi:10.1016/j.ygyno.2008.08.030.

40. Goldie SJ, Kim JJ, Wright TC. Cost-effectiveness of human papillomavirus DNA testing for cervical cancer screening in women aged 30 years or more. Obstet Gynecol. 2004;103(4):619-31. doi:10.1097/01.AOG. 0000120143.50098.c7.

41. Goldie SJ, Gaffikin L, Goldhaber-Fiebert JD, et al. Cost-effectiveness of cervical-cancer screening in five developing countries. N Engl J Med. 2005;353(20):2158-68. doi:10.1056/NEJMsa044278.

42. Goldie SJ, Kuhn L, Denny L, Pollack A, Wright TC. Policy analysis of cervical cancer screening strategies in low-resource settings: clinical benefits and cost-effectiveness. JAMA J Am Med Assoc. 2001;285(24):3107-15.

43. Kim JJ, Wright TC, Goldie SJ. Cost-effectiveness of human papillomavirus DNA testing in the United Kingdom, The Netherlands, France, and Italy. J Natl Cancer Inst. 2005;97(12):888-95. doi:10.1093/jnci/dji162.

44. Mandelblatt JS, Lawrence WF, Womack SM, et al. Benefits and costs of using HPV testing to screen for cervical cancer. JAMA J Am Med Assoc. 2002;287(18):2372-81.

45. Kulasingam SL, Rajan R, St Pierre Y, Atwood CV, Myers ER, Franco EL. Human papillomavirus testing with Pap triage for cervical cancer prevention in Canada: a cost-effectiveness analysis. BMC Med. 2009;7:69. doi:10. 1186/1741-7015-7-69.

46. Sherlaw-Johnson C, Philips Z. An evaluation of liquid-based cytology and human papillomavirus testing within the UK cervical cancer screening programme. Br J Cancer. 2004;91(1):84-91. doi:10.1038/sj.bjc.6601884.

47. Berkhof J, Coupé VM, Bogaards JA, et al. The health and economic effects of HPV DNA screening in The Netherlands. Int $J$ Cancer. 2010;127(9):2147-58. doi:10.1002/ijc.25211.

48. de Kok IMCM, van Rosmalen J, Dillner J, et al. Primary screening for human papillomavirus compared with cytology screening for cervical cancer in European settings: cost effectiveness analysis based on a Dutch microsimulation model. BMJ. 2012;344, e670.

49. van Rosmalen J, de Kok IMCM, van Ballegooijen M. Cost-effectiveness of cervical cancer screening: cytology versus human papillomavirus DNA testing. BJOG Int J Obstet Gynaecol. 2012;119(6):699-709. doi:10.1111/j. 1471-0528.2011.03228.x.

50. Eversole GM, Moriarty AT, Schwartz MR, et al. Practices of participants in the college of american pathologists interlaboratory comparison program in cervicovaginal cytology, 2006. Arch Pathol Lab Med. 2010;134(3):331-5. doi:10.1043/1543-2165-134.3.331.

51. Ratnam S, Franco EL, Ferenczy A. Human papillomavirus testing for primary screening of cervical cancer precursors. Cancer Epidemiol Biomark Prev. 2000;9(9):945-51.

52. Kulasingam SL, Hughes JP, Kiviat NB, et al. Evaluation of human papillomavirus testing in primary screening for cervical abnormalities: comparison of sensitivity, specificity, and frequency of referral. JAMA J Am Med Assoc. 2002;288(14):1749-57.

53. Kitchener HC, Almonte M, Thomson C, et al. HPV testing in combination with liquid-based cytology in primary cervical screening (ARTISTIC): a randomised controlled trial. Lancet Oncol. 2009;10(7):672-82. doi:10. 1016/S1470-2045(09)70156-1.

54. Wright TCJ, Stoler MH, Sharma A, et al. Evaluation of HPV-16 and HPV18 genotyping for the triage of women with high-risk HPV+ cytologynegative results. Am J Clin Pathol. 2011;136(4):578-86. doi:10.1309/ AJCPTUS5EXAS6DKZ

55. Wong AA, Fuller J, Pabbaraju K, Wong S, Zahariadis G. Comparison of the hybrid capture 2 and cobas 4800 tests for detection of high-risk human papillomavirus in specimens collected in PreservCyt medium. J Clin Microbiol. 2012;50(1):25-9. doi:10.1128/JCM.05400-11. 